\title{
GENETIC AND SOMATIC ABERRATIONS IN TWO ASYM- METRICALLY MARKED FOWLS FROM SEX-LINKED CROSSES
}

\author{
A. W. GREENWOOD and J. S. S. BLYTH \\ Poultry Research Centre, King's Buildings, Edinburgh 9

\section{INTRODUCTION} \\ Received 24.v.50
}

IN the course of an account of an investigation of 7 possible cases of somatic mutation in the guinea-pig, Wright and Eaton (1926) have pointed out that, though many instances of the phenomenon have been observed in Drosophila, it is seldom that information about the genetic situation is available in the less frequent reports of its occurrence in vertebrates. That this is still true for birds is clear from the review and discussion by Crew and Munro (:938) of gynandromorphism and lateral asymmetry in this class ; in it their enterprising theory, accommodating all known cases by accounting for slight lateral asymmetry on grounds of chromosome loss, and the larger bilateral differences in size as due to non-disjunction, rests on the absence of contradictory evidence rather than on positive factual support.

The value of these apparent deviations from the known laws of inheritance for further elucidating genetic mechanisms in higher animals, and the comparative rarity of their identification, make it important that experimental evidence concerning them, even if incomplete, should be put on record. It is with this in mind that the breeding records of two visibly abnormal birds of this kind are detailed and discussed in the present paper.

\section{MATERIAL}

Both birds were males from the same sex-linked cross, Light Sussex female by Rhode Island Red male, but they arose three years apart and, so far as is known, in unrelated flocks.* As the progeny of this particular cross these males ought to have exhibited the sexlinked epistatic silver plumage of their dams. They ought also to have been heterozygous for yellow/white leg and skin colour and to have manifested the dominant autosomal white. Both showed lateral asymmetry in leg and skin colour, being white on the right side and yellow on the left.

Bird fr.-Bilaterality in plumage colour, silver on the right, red

* We are indebted to Mr R. Scott Miller, Pittachar, Crieff for the first of these birds, while the second was obtained through the kind offices of Miss A. Bowie, West of Scotland Agricultural College Poultry School. 
left, was the most striking feature of this bird in which the line of demarcation in both skin and plumage followed the midline of the bird most accurately, even to the tip of the beak (plate I). On neither side was the colour completely pure ; on the silver, i.e. " normal" side, odd red feathers occurred and they seemed to increase in frequency with age, though throughout his life this side remained predominantly silver and the irregularities are probably not greater than would be expected in an ordinary male from this cross where silver, though definitely epistatic, is rarely completely so. A certain amount of white on the tips of the red feathers of the " recessive" side was less explicable until the breeder of the bird proffered the information that this appeared to be a hereditary defect which he had occasionally noted in his flock.

Bird 72.- This fowl was also bipartite in colour but the division line was less obvious and there was a tendency for the red to spread beyond the confines of the left to the right or silver side. In particular the dorsal surface of the right wing was mainly red but this may give a false idea of the greater extension of colour since it has its embryological origin close to the mid line. Round the base of the comb there was a cap of purely silver feathers.

In both birds the comb was twisted over to the left or red side, and as it was of the small, stiff, thick variety common to this cross there seemed no reason for this phenomenon other than differential development on the two sides of the body. Both birds had a noticeably larger right wattle but variability as great has been noted in normal purebred Brown Leghorns, where either wattle may be the longer. Their spur lengths were as follows :

$$
\text { J2/Rt. } 2 \cdot 9 \mathrm{~cm} \text {. Left } 3 \cdot 7 \mathrm{~cm} \text {. Ji Rt. } 5 \cdot 5 \mathrm{~cm} \text {. Left } 4 \cdot 2 \mathrm{~cm} \text {. }
$$

While there was nothing obvious in the gait or stance of the birds to suggest that this asymmetry extended to their skeletal structure, it may be noted that both suffered from "bumble foot" and in both it was the left foot that was affected. It was this condition which led to a septicæmia in JI, and the bird was destroyed in poor condition on 2 oth December 1948 when 5 years old. J2 now in his second year is still alive.

Bird Fr.-Post-mortem examination of J I showed the septicæmia to have been widespread and to have resulted in pathological lesions in practically every organ of the body. Both his testes were inactive ; that on the left weighed $0.52 \mathrm{gm}$. and on the right $0.80 \mathrm{gm}$.; no size difference was discernible between the vasa deferentia. Histologically the spermatic tubules were small, with lumina obliterated by degenerating cells and cell debris; their germinal lining was scanty and only a few spermatocytes were to be seen. As is usual in quiescent testes there was marked hyperplasia of the interstitial tissue.

Lengths of the main bones of the appendicular skeleton are given in table I with those for Crew's ( $19^{28}$ ) extreme case of lateral 
asymmetry from the same cross for comparison. The measurements were made by slide caliper to the nearest millimetre. It is clear that the differences between left and right side are of a small order and

TABLE I

Bone lengths (in mm.), $\mathcal{F}_{I}$ and Crew's 1928 case

\begin{tabular}{|c|c|c|c|c|}
\hline \multirow[b]{2}{*}{ Bone } & \multicolumn{2}{|c|}{$J_{I}$} & \multicolumn{2}{|c|}{ Crew's case } \\
\hline & Left side & Right side & Left side & Right side \\
\hline $\begin{array}{l}\text { Humerus } \\
\text { Radius }: \\
\text { Ulna : } \\
\text { Carpo-metacarpus } \\
\text { Femur }: \\
\text { Tibia }: \\
\text { Scapula }: \\
\text { Coracoid }:\end{array}$ & $\begin{array}{r}100 \\
89 \\
99 \\
55 \\
\text { II4 } \\
\text { I64 } \\
96 \\
75\end{array}$ & $\begin{array}{r}98 \\
88 \\
97 \\
54 \\
114 \\
167 \\
97 \\
73\end{array}$ & $\begin{array}{l}97 \\
88 \\
107 \\
54 \\
107.5 \\
165 \\
94 \\
75.5\end{array}$ & $\begin{array}{l}81 \\
79 \cdot 5 \\
88 \\
52 \\
72 \\
135 \cdot 5 \\
88 \\
62\end{array}$ \\
\hline Total lengths . & $79^{2}$ & 788 & 788 & $65^{8}$ \\
\hline
\end{tabular}

not consistent in direction; the right tibia is $3 \mathrm{~mm}$. longer than the left but it is the left coracoid which exceeds its homologue by $2 \mathrm{~mm}$. This results in a net difference between the two sides of only $4 \mathrm{~mm}$. in 790, or about 0.5 per cent. This is smaller than the $2-4$ per cent. difference which characterised Crew and Munro's less asymmetrical group. On the other hand, the individual bones appear to show greater variability than was found in a series of normal fowls by Hutt (1929) who reported that in the majority of cases measurements of paired bones were coincident and only in rare cases was a difference greater than $0.5 \mathrm{~mm}$. met with.

Comparison with Crew's (1928) case shows a remarkably close agreement between the length of the bones on the left side of this bird and those of Ji, only the ulna and femur showing a noticeable discrepancy.

Since the traceable abnormalities in the two birds related to the exhibition of maternal "dominant" and paternal " recessive" characters (which themselves constituted breed differences in the parents) in one and the same individual, the most obvious course would have been to backcross them to one or both parental breeds. However, a policy of avoiding as far as possible the introduction of strange birds into the Centre's plant (as a disease prevention tactic) led to a different course being pursued, and they were mated to surplus hens from the home-bred Brown Leghorn flock. Like R.I.R. plumage that of the Brown Leghorn is hypostatic to silver. In addition to the first crosses a further generation has been raised from the progeny of Ji by mating some of them $(a)$ to Brown Leghorns, and (b) among themselves. 
While the small number of silver chicks in the first hatch from JI was sufficient to indicate that he was abnormal germinally as well as somatically, it was not until considerable numbers of progeny had been reared from both males that the full complexity and interrelations in the data collected became apparent.

All the characters examined could not be classified at the same time and thus have not been observed in the same size of sample : this resulted because silver could be identified in the down plumage at hatching but gold-a new segregating colour-could not be distinguished from the paternal-type red until definitive feathers had developed; it was also at least 6 weeks after hatching before white and yellow leg colour could be satisfactorily differentiated, and sometimes longer when, as often, yellow showed a wide range of intensity. Chicks were sexed when the secondary sex characters allowed, or from examination of the sex glands if they died earlier. As a rule all chicks were examined at hatching and a sample of each group retained for re-examination at 8 weeks or older. Even when the desirability of carrying an unselected sample through to the second stage examination was realised, it was not always possible to do so : birds died, and lack of space or other demands on chick supplies made inroads on many of the hatches.

These variables cause difficulties of interpretation and might make confusing a normal sequential treatment of data leading to integration, so the main results are first set out in the form of a generalised but uncritical summary (table 2) and followed by individual analyses of the various points which require further elucidation and assessment.

\section{Incubation records}

$\mathcal{F}_{I}$. Infertility and embryonic mortality in eggs from the mates of the two males show a curious reversal in degree of incidence. For Ji incubations were made for a 3-year period but mainly outside the normal hatching season (in May, June, August and October to January inclusive). Under such conditions fertility was surprisingly good and might have been regarded as a manifestation of hybrid vigour resulting from a three-way cross had not embryonic deaths been rather higher than in purebred Brown Leghorn eggs, incubated at approximately comparable periods. $\mathrm{A}$ chi $^{2}$ test (percentages weighted for actual numbers) indicated a lack of uniformity in the distribution of dead-in-shell among the hatches ( $p$ I per cent., $d f$ I 2 ) but this was traced to 2 lots, totalling 70 eggs set in October and the beginning of November 1944, in which 30 out of 65 fertile eggs failed to hatch ; their elimination raised the probability of homogeneity to 30 per cent. and brought the mean death rate more in line with that for purebreds. As this is the time of year when spermatogenic activity is at its nadir in fowls, and may cease altogether in individual males, the higher mortality among Ji embryos might be attributable 
to some seasonal physiological"weakness in the male gamete and need not, prima facie, require any out of the ordinary explanation.

TABLE 2

Asymmetrical cocks mated to pure Brown Leghorn hens

\begin{tabular}{|c|c|c|c|c|c|c|c|}
\hline & & & & & $\mathrm{J}_{\mathrm{I}}$ & \multicolumn{2}{|c|}{$\mathrm{J}_{2}$} \\
\hline Eggs set & . & . & . & $\cdot$ & 583 & \multicolumn{2}{|c|}{755} \\
\hline $\begin{array}{c}\text { Per cent. } \\
\text {," } \\
\text {," }\end{array}$ & $\begin{array}{l}\text { Infertility } \\
\text { embryonic } \\
\text { fertiles hatcl } \\
\text { hatched of a }\end{array}$ & $\begin{array}{l}\text { tality } \\
\text { g. }\end{array}$ & $:$ & $\dot{.}$ & $\begin{array}{r}8 \cdot 2 \\
21 \cdot 1 \\
77 \cdot 0 \\
70 \cdot 7\end{array}$ & \multicolumn{2}{|c|}{$\begin{array}{c}30 \cdot 1 \\
7 \cdot 15 \\
89 \cdot 8 \\
62 \cdot 8\end{array}$} \\
\hline Day-old ch & icks recorded & & & & 393 & \multirow{2}{*}{\multicolumn{2}{|c|}{$\begin{array}{r}3^{81} \\
45^{\cdot 6} \\
27^{\circ} 0\end{array}$}} \\
\hline $\begin{array}{c}\text { Per cent. } \\
\quad,\end{array}$ & $\begin{array}{l}\text { males } \\
\text { Silvers }\end{array}$ & $\dot{.}$ & : & . & $\begin{array}{r}48 \cdot 8 \\
5 \cdot 6\end{array}$ & & \\
\hline Juvenile bir & rds recorded & . & . & . & $205^{*}$ & $25^{I}$ & I $52 \dagger$ \\
\hline $\begin{array}{c}\text { Per cent. } \\
, " \\
, "\end{array}$ & $\begin{array}{l}\text { Reds. } \\
\text { Silvers } \\
\text { Gold . } \\
\text { White Legs }\end{array}$ & $\dot{.}$ & $: \quad:$ & $\dot{.}$ & $\begin{array}{c}89 \cdot 0 \\
7 \cdot 0 \\
(3 \cdot 5) \\
(6 \cdot 0\end{array}$ & $\begin{array}{l}57 \cdot 8 \\
30 \cdot 3 \\
\mathrm{II} \cdot 9 \\
33 \cdot 1\end{array}$ & $\begin{array}{l}60 \cdot 6 \\
27 \cdot 6 \\
11 \cdot 8 \\
34 \cdot 2\end{array}$ \\
\hline ", & $\begin{array}{l}\text { Silver Whit } \\
\text { Gold White } \\
\text { Red White/ }\end{array}$ & $\begin{array}{l}\text { otal W } \\
\text { tal Wh } \\
\text { cal Wh }\end{array}$ & $\begin{array}{l}\text { hite Legs } \\
\text { ite Legs } \\
\text { ite Legs }\end{array}$ & : & $\begin{array}{c}5^{8} \\
\left(4^{2}\right) \\
0\end{array}$ & $\begin{array}{l}53 \\
15 \cdot 7 \\
31 / 3\end{array}$ & \\
\hline 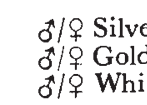 & $\begin{array}{l}\text { ers } \\
\text { dite Legs }\end{array}$ & $:$ & $:$ & $\dot{.}$ & $\begin{array}{l}6 / 15+1 \\
2 / 5 \\
2 / 10\end{array}$ & $\begin{array}{l}35 / 66+ \\
11 / 19 \\
3^{1} / 5^{2}\end{array}$ & \\
\hline
\end{tabular}

* From Ji, I Black " Duckwing" Type male with White Legs unclassified-possibly a silver.

$\dagger$ Restricted sample.

As the condition of the incubating eggs was examined in the normal way by candling (i.e. holding over a bright light) it was inevitable that a percentage of very early deaths would be recorded as infertiles, and the low mortality and fertility in the data from $\mathrm{J}_{2}$ at once suggested that an abnormally large number had been so classified. Deaths during the incubation period show a characteristic distribution in the fowl, forming 2 high peaks, one around the 3 rd day of incubation and the other from the I8th day to hatching (2I days). If the postulate just made were effective then the mis-classification of non-viable zygotes as infertiles should have resulted in a reduction of early embryonic deaths below the expected numbers. That this was not so is borne out by the actual figures for $4 \mathrm{I}, 3$ and Io embryos died in the 1 st, 2nd and 3 rd week respectively and this is the exact reverse of the situation deduced.

Reasons for the high infertility must therefore be sought in other directions and it is regrettable that the good results with $\mathrm{J}$ I led to 
the view that the labour entailed in pedigreeing the eggs from the individual mates of this one was unnecessary, for it has left open the possibility that though a most vigorous bird, he was showing preference for particular mates and leaving a number of other hens unfertilised.* The only other points which can be made here are that the incubations were carried out between February and June, a time when the best hatching records are to be expected, and that the percentage of infertility showed no undue variation among the different hatches : a $\mathrm{chi}^{2}$ test yielded a probability of homogeneity over 30 per cent., $d f$ I 3 .

External characters.-Despite the wealth of experimental data on the inheritance of morphological characters in the fowl, Jull's (I940) review reveals that though there is a good deal of loose information about the behaviour of isolated pairs of traits there is far from a sufficiency of integrated evidence about the genetic constitution of various breeds on which to predict segregations from particular crosses. In regard to the three breeds concerned in the cross under consideration, Light Sussex, R.I.R., and Brown Leghorn, the only sound lead available is that the silver plumage of the Light Sussex behaves as a sex-linked dominant unit in relation to the other two types. This difference is distinct in so far as it relates to silver and non-silver but takes no account of the intra-class variation which is considerable in the present case. Neither Brown Leghorn nor R.I.R. plumage types appears to be allelic to silver so that the sex-linked effect rests on epistasis and this favours the segregation of hidden colours or pattern in the triple cross.

Actually the variation encountered could be regarded mainly as different degrees of modification of the parental types and in only one case has it been necessary to recognise an additional class, gold, for our present purposes. It may also be noted that indication of Brown Leghorn ancestry are traceable in the feathering of most non-silvers and takes the form of an imposition of Brown Leghorn pattern on the ground colour of other types with all degrees of effectiveness, from that giving a mismarked R.I.R. plumage at one end of the scale to that giving a mismarked Brown Leghorn type at the other; in the silver class is showed its influence in the appearance of "duckwing " patterns, and their female homologues but only in a proportion of cases.

As already mentioned it was noticeable at hatching that the number of silver-plumaged progeny of Ji was far below the expected ratio of 50 per cent. though they appeared in all but one of the settings in numbers varying from one to three; it was not until the birds were several weeks old that a like shortage of white-legged individuals was evident. At first it appeared that white legs were restricted to

* Recent matings of $\mathrm{J}_{2}$ to trap-nested hens have indicated that his low fertility is due to infrequent matings : females show periods of infertility interspersed with sequences of fertile eggs. 
the silver group but then they turned up in rare non-silver birds; these were much paler than the average of the group and have been designated gold in opposition to the more definite shades of red though there was no clear cut demarcation between them. In respect of the data from the first male alone the decision to regard them as separate classes was open to considerable doubt and it might have been argued that the genes regulating leg colour were having a diluting effect on plumage colour for only a single gold bird with yellow legs was identified. The postulate had the advantage, however, of rationalising the relation found between leg colour and plumage : about half the white-legged birds were gold and half silver and there were 7 silver white and 7 silver yellows. The lack of a similar relation between gold whites and gold yellows is accounted for by lack of ability to identify the latter class. Despite their numerical weakness such classes were strongly suggestive of the idea that they derived from a small part of the germinal tissue which, apart from the absence of red, was behaving normally and producing gametes in the $\mathrm{I}: \mathrm{I}$ ratio expected from monohybrid heterozygotes; the remainder of the testes was then defective in that it carried neither the genes for white legs nor for silver.

When descriptions of J2's progeny became available it was seen that the same groups were again segregating but that there was an additional class-red plumage with white legs. Though still below the expected value of 50 per cent. the frequency of silver is much greater here, yet again approximately half the silver birds were white-legged and half the white-legged ones were silvers.

It is of some importance to decide how reliable the size classes are here : the figure of 27 per cent. obtained for the silvers at hatching might be taken as indicating a parameter of 25 per cent. which would accord with a postulate that one testis was producing silver gametes in the normal ratio while the other lacked the gene entirely. At the second examination the proportion had risen to 30 per cent. indicating that discrimination, artificial or otherwise, against non-silvers had operated between the two dates. If this fell mainly upon gold, as it might by chance or through differential viability it could markedly affect the size of the group. The only check on this is to compare the frequency of the segregating classes in the more complete groups ( 152 chicks) with that for all. Table 2 (restricted sample) shows that this is practically without effect on the percentage of golds, and though the silvers return to a value approaching that in the day-old ratio, it is the reds, not the golds which profit from their loss.

From the analyses of the second stage examination (table 3 ) it can be seen that silver white, silver yellow, and red-plus-gold white constitute classes of approximately equal size but that red-plus-gold yellow is about three times as large. This suggests that the gonadal situation is similar to that in the first half-sider in that there is again one part of the germinal tissue which is deficient as to silver and white 
(responsible for the excess in the red-plus-gold yellow class) and another which is behaving more or less according to expectation; it is in fact behaving more normally than in the first cock for, since

TABLE 3
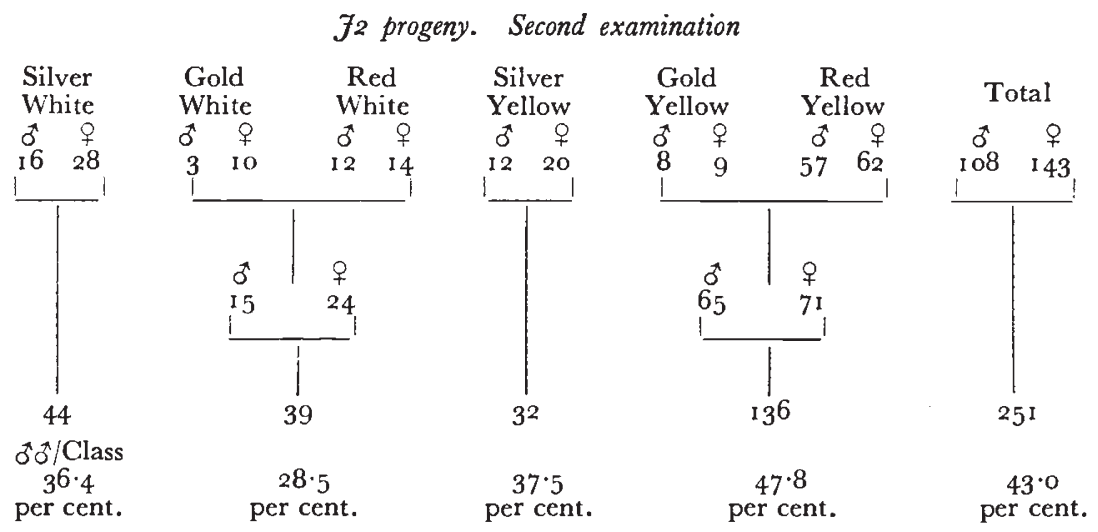

Note.-Though ignorant of the exact situation, particularly in regard to dominance and allelism in some of the characters examined in the crosses, it may aid in understanding the interpretation put upon the segregations listed above and in table 6 if the matings are represented by simple genetic formulæ which can accommodate the results without prejudice to these gaps in our knowledge. The letters $\mathrm{S}$ and $\mathrm{W}$ are in common usage as symbols for the sex-linked gene producing silver plumage and the autosomal one for white skin and leg colour respectively. In addition, for the present purpose, $\mathrm{R}$ may represent R.I.R. plumage colour and B, the Brown Leghorn type; the corresponding small letters denote the absence of the genes causing these manifestations, but with one addition: while $\mathrm{r}$ represents the absence of the basis of R.I.R. colour in the Brown Leghorn, let $\rho$ indicate its absence in the presence of Light Sussex colour genes. The "genes" presumed to come from the sire are above the line in each individual's formula, those from the dam, below. No linkage is inferred.

On this basis the cross between $\mathrm{J}_{2}$ and Brown Leghorn females would be :-

$$
\begin{aligned}
& \frac{\mathrm{sRbw}}{\overline{\mathrm{S}} \mathrm{\rho bW}} \times \frac{\mathrm{sr} \mathrm{Bw}}{-\mathrm{rBw}} \text { and their male progeny should have included } \\
& \text { Reds : } \frac{s R b w}{s r B w} \text { or } \frac{s R b W}{s r B w} \\
& \text { Golds : } \frac{s \rho b w}{s r B w} \text { or } \frac{s \rho b W}{s r B w} \\
& \text { Silvers : } \frac{S \rho b w}{\mathrm{srBw}} \quad \frac{S \rho b W}{\mathrm{srBw}} \frac{\mathrm{SRbw}}{\mathrm{srBw}} \text { or } \frac{\mathrm{SRbW}}{\mathrm{srBw}}
\end{aligned}
$$
missing.

The female progeny should comprise the same groups but in each case with the lower $s$ silver and red are non-allelic, the heterozygote mated to the Brown Leghorn should yield two classes in the recessive half of its progeny, R.I.R. red and its allele or complementary group from Light Sussex or Leghorn.

On a unit basis of inheritance then, the number of golds does not fall far below expectation for the two classes should be the same, and together equal that for silvers. Further evidence in support of this was actually available from the latter though exact data are lacking 
as its significance was not at first realised. Two main classes were recognised among the silvers_- "self" and " duckwing." The amount of non-silver in the latter varied a good deal and closer inspection revealed that it was possible to split the class into those in which the colour on the back and wing was the red-gold hue of the Brown Leghorn and others in which it was the darker, flatter colour of the R.I.R. Presumably a similar genetic dichotomy was present in the self silvers but could not be expressed. Thus, on the assumption that one testis was normal, we might expect the progeny from it to segregate in four groups each accounting for I 2.5 per cent. of the cock's total offspring, silver non-red, silver plus red, non-silver non-red (i.e. gold), and nonsilver plus red. Since all the chicks from the other testis would fall into the latter category, the distinguishable classes expected would be 25 per cent. silvers, 12.5 per cent. golds and 62.5 per cent. reds which is very close to the actual proportions obtained.

Sex ratios.-A notable feature of table 3 which has not yet been mentioned is the shortage of males in three of the four main classes and the consistency of this phenomenon in both cocks' offspring must now be examined. With a figure of 48.8 per cent. males there seemed nothing remarkable about the sex ratio of chicks from $\mathrm{J}$, and the preponderance of females in the rare gold and silver plumage, and white-legged, classes could be regarded as a chance result of small numbers until the same bias was found in the data from $\mathrm{J}_{2}$ for these groups. The substantiation or refutation of this phenomenon is of some import, for in birds the male is the homogametic sex and does not normally control determination of sex in his offspring. Though the three affected classes in table 3 are very alike in their proportion of males, they are again suspect because of the incomplete hatching groups, but use can be made of the fact that silvers are identifiable at hatching to obtain ratios for nearly complete samples at that date (table 4). This actually enhances the shortage of silver males but unexpectedly gives a non-silver group in which the sexes are nearly equal. Whatever the situation in the latter it is difficult to avoid the conclusion that the silvers are abnormally distributed as to sex. Among the separate hatches only two show an excess of males (each 4 주 3 우우) and when they are grouped as indicated in the table to form samples of a more uniform total size $\left(5^{6-69)}\right.$ the trend is even more convincing: the six silver groups so obtained have an average of 5.83 o $\delta$ and $\mathrm{I}$ I $\mathrm{O}$ 웅, giving a mean difference of 5.17 birds with a standard error of $\mathrm{I} \cdot 47$; in the larger non-silver group the comparable mean difference is $0 \cdot 67 \pm 2 \cdot 43$.

For both classifications there has been a differential wastage of the sexes between the two examinations. It might have come about through natural causes, expressed in mortality, or artificially through culling of more males. These sources of loss are analysed in table 5 : equal numbers of silvers were disposed of, but I 3 우 and only I 0 t are recorded as having died. Among the non-silvers the sexes died 
in equal numbers but $37 \delta \delta$ and 25 우 were culled ; their inequality at the second examination is, therefore, due to chance in culling; since this was not consciously based on health traits, there are no

TABLE $_{4}$

$\mathcal{F}_{2}$ progeny. First examination

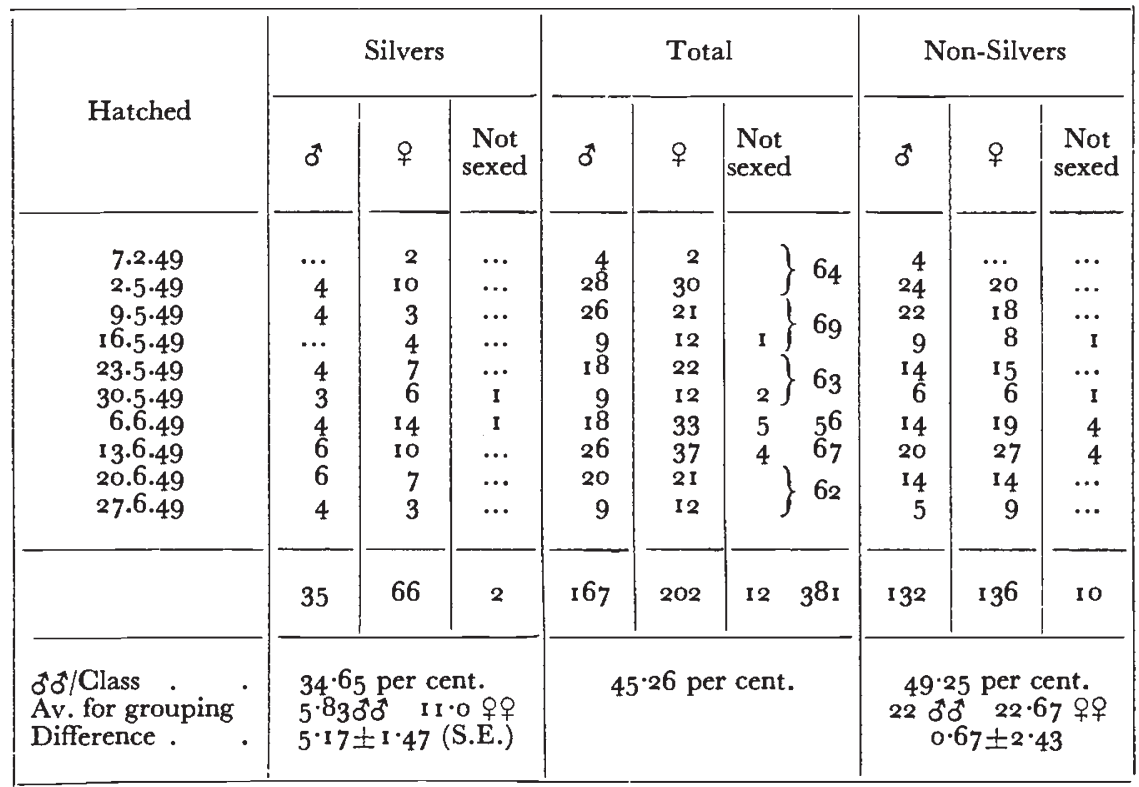

TABLE 5

Source of Loss between first and second examination

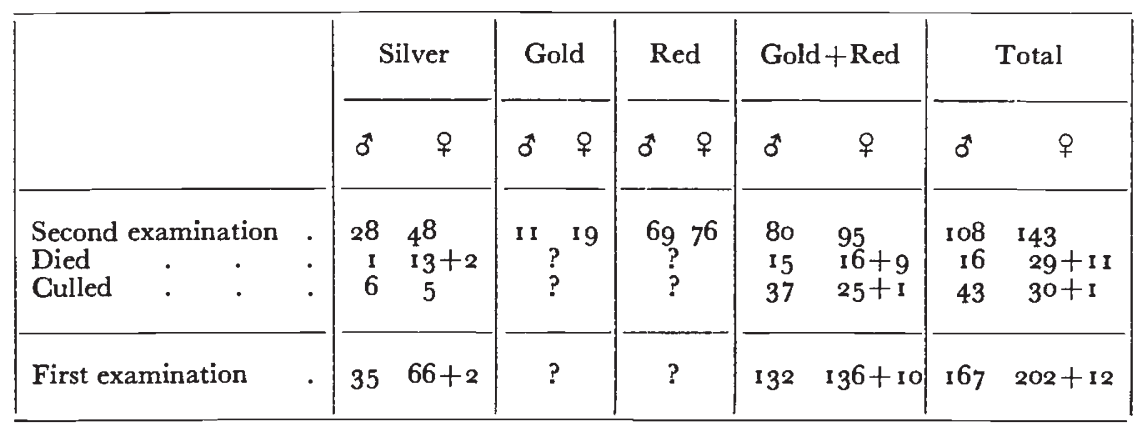

observational grounds to support the idea of an abnormal sex ratio here. If, however, the postulate still remained open on other premises it may be noted that there are three possible ways in which the phenomenon might operate : it might be affecting $(a)$ the golds alone, $(b)$ the white-legged non-silvers, or $(c)$ the entire group postulated to be homologous to the silver one. In the present sample, either of the first two conditions could occur without causing more 
bias than there is in the non-silver group at hatching, but in the third case a contrary, compensatory ratio in the remainder of the red, yellow-legged birds would be necessary to achieve this.

Backcrosses of $\mathcal{F} I$.-Breeding from the progeny of $\mathrm{J} I$ served firstly in the search for any peculiarities he might have passed on, and secondly to check how the observed traits were being inherited. Nothing unaccountable was observed in their breeding behaviour, or in the appearance of the small groups of offspring raised from each mating. Out of $46 \mathrm{I}$ chicks hatched from the various tests, 204 were males and 44 unsexed. If there was any tendency to an excess of females it was in the crosses of 5 red $F_{1}$ hens with a Brown Leghorn and later a gold cock (39 $\sigma^{\star}: 49$ 우 +6$)$ but this bias appeared non-significant when I I $\widehat{\partial} \partial$, I 8 우 and 5 unsexed chicks, the progeny of one dam, were excluded.

The crosses made and the situation found with regard to plumage and leg colour are summarised in table 6 . The females used were $F_{1}$ from the mating of $J_{I}$ with Brown Leghorn hens except for four golds indicated in the table; these were two pairs of progeny of a Brown Leghorn cock mated to a silver and a gold hen respectively. The males used were a purebred Brown Leghorn, an $F_{1}$ silver, and $F_{1}$ gold, and an $F_{1}$ red Brown Leghorn type cock; no progeny from the last bird were available for a second examination so data from it are based on day-olds. In all $F_{1}$ matings the Brown Leghorn genotype should be present in the heterozygous state in each side of the cross. In the backcross $F_{1}$ to Brown Leghorn male there are three gametic complements of Brown Leghorn genes available for segregation in the progeny, and with the few gold hens from this cross, used in further tests, there may be theoretically up to the same maximum.

The summarised test matings for white and yellow leg colour accord well with a monohybrid ratio; the slight excess of yellows in the backcross is due to the higher proportion from two of the three red females mated to a gold cock $(4: 7$ and $3: 9)$ but the third red dam produced 8 white and 8 yellow-legged offspring.

Silver plumage when taken in apposition to the absence of silver in the other three groupings behaves as a sex-linked unit dominant to them all. Gold also can be regarded as a simple dominant to Brown Leghorn type (though the pattern of the latter is present to varying degrees) but the evidence as to the relations of red and gold, and red and Brown Leghorn is not conclusive. Inherited on a simple basis, if gold were dominant to red, but non-allelic, the expected classes from mating their $F_{1}$ representatives would be 2 gold : I red : I not red or gold, but if the situation were reversed the ratio would be 2 red : I gold : I not red or gold. The results appear to be in better agreement with the second postulate. If this were so, whether gold were carried by the red birds or not, the appearance of red, gold, and Brown Leghorn individuals as progeny of this cross is according to expectation. Gold carried by the red $F_{1}$ birds however, would be 
expected to segregate out when they were crossed with Brown Leghorns, but there it has not been identified.

We are thus left with the suggestion that red is dominant to gold, and incompletely so to Brown Leghorn pigmentation. In the reds tested it does not appear likely that gold is present, nor is there any evidence that silvers were carrying red, for this colour did not appear

TABLE 6

FI backcross progeny

\begin{tabular}{|c|c|c|c|c|c|}
\hline \multicolumn{6}{|c|}{ Plumage } \\
\hline \multirow{2}{*}{ Sire } & \multirow{2}{*}{ Dam } & \multicolumn{4}{|c|}{ Progeny } \\
\hline & & $\begin{array}{l}\text { Sex ratio } \\
0 \stackrel{+}{0}\end{array}$ & \multicolumn{2}{|c|}{ Plumage } & $\begin{array}{l}\text { Main ratio } \\
\text { expected }\end{array}$ \\
\hline Pure Br. L. & $\begin{array}{l}\times \text { Silver } \\
\times \text { Gold } \\
\times \text { Red }\end{array}$ & $\begin{array}{rr}5 & 9 \\
22 & 25 \\
12 & 12\end{array}$ & \multicolumn{2}{|c|}{$\begin{array}{l}5 \text { Silver } 9 \text { non-Silver (3 Gold } 6 \text { Br. L.) } \\
23 \text { Gold } 24 \text { non-Gold (all Br. L.) } \\
9 \text { Red I } 5 \text { non-Red (all Br. L.) }\end{array}$} & $\begin{aligned} 7 & : 7 \\
23 \cdot 5 & : 23 \cdot 5 \\
12 & : 12\end{aligned}$ \\
\hline \multicolumn{2}{|c|}{$\begin{aligned} & \text { Red Br. L. } F_{1} * \times \text { Silver } \\
& \times \text { Gold }\end{aligned}$} & $\begin{array}{rr}7 & 5 \\
11 & 14\end{array}$ & \multicolumn{2}{|c|}{$\begin{array}{l}7 \text { Silver } 5 \text { non-Silver } \\
\text {... Silver } 25 \text { non-Silver }\end{array}$} & $\begin{array}{l}6 \cdot 6 \\
\quad: 25\end{array}$ \\
\hline Gold $F_{1}$ & $\begin{array}{l}\times \text { Silver } \\
\times \text { Gold } \uparrow \\
\times \text { Red }\end{array}$ & $\begin{array}{rr}9 & 7 \\
5 & 5 \\
18 & 21\end{array}$ & \multicolumn{2}{|c|}{$\begin{array}{l}9 \text { Silver } 7 \text { non-Silver ( } 5 \text { Gold } 2 \text { Br. L.) } \\
9 \text { Gold I non-Gold (Br. L.) } \\
20 \text { Red I } 9 \text { non-Red (12 Gold } 6 \text { Br. L. I Buff) }\end{array}$} & $\begin{aligned} 8 & : 8 \\
7 \cdot 5 & : 2 \cdot 5 \\
19 \cdot 5 & : 19 \cdot 5\end{aligned}$ \\
\hline \multicolumn{2}{|c|}{$\begin{aligned} \text { Silver Backcross } & \times \text { Silver } \\
& \times \text { Gold }\end{aligned}$} & $\begin{array}{ll}\text { I8 } & 19 \\
\text { I3 } & 19+\mathrm{I}\end{array}$ & \multicolumn{2}{|c|}{$\begin{array}{l}29 \text { Silver } 8 \text { non-Silver (4 Gold } 4 \text { Br. L.) } \\
\text { I6 Silver I } 7 \text { non-Silver ( I I Gold } 6 \text { Br. L.) }\end{array}$} & $\begin{array}{r}28: 9 \\
\text { I } 6 \cdot 5: 16 \cdot 5\end{array}$ \\
\hline & \multicolumn{4}{|c|}{ LEG CoLOUR } & \\
\hline & \multirow{2}{*}{\multicolumn{2}{|c|}{ Parents }} & \multicolumn{2}{|c|}{ Progeny } & \\
\hline & & & Observed & Expected & \\
\hline & \multicolumn{2}{|c|}{$\begin{array}{l}\text { White } F_{1} \times \text { White } F_{1} \\
\text { White } F_{1} \times \text { Yellow } \\
\text { Yellow } \times \text { Yellow }\end{array}$} & $\begin{array}{c}\text { White Yellow } \\
49: 15 \\
60: 70 \\
\ldots: 24\end{array}$ & $\begin{array}{c}\text { White Yellow } \\
4^{8}: 16 \\
65: 6_{5} \\
\ldots: 24\end{array}$ & \\
\hline
\end{tabular}

in the progeny of any of the 3 silver hens and cock tested. Hutt (1949) considers that all birds are basically either silver or gold and that the two colours are sex-linked and allelic. In the present case gold has shown no indication of sex linkage and though there was ample opportunity in the gold female $\times$ Brown Leghorn male matings the plumage types showed no abnormality of distribution in relation to sex. Its behaviour thus is more in line with the gold described by Punnett (1948) which he concluded to be autosomal. 


\section{DISCUSSION}

The similarity in the expression of the somatic and germinal abnormalities in both $\mathrm{J}_{1}$ and $\mathrm{J}_{2}$ suggests they have a common origin very early in ontogeny and prior to the migration of the presumptive primordial germ cells into the embryonic gonads.

Since in $\mathrm{J}_{\mathrm{I}}$ the external manifestation was bilateral, and in $\mathrm{J}_{2}$ roughly so, the irregularity could not have taken place later than the

TABLE 6 (continued)

Possible formula for the plumage of sires and dams used (see table 3 for explanation of symbols)

Sire

Pure Br. L. . $\frac{\text { srB }}{\text { srB }}$

Red Br. L. F $F_{1} \cdot \frac{s R b}{s r B}$

Gold $F_{1} \cdot \quad \cdot \frac{s \rho b}{s r B}$

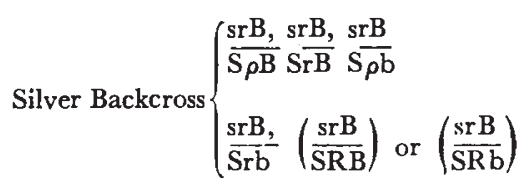

$$
\begin{array}{ll} 
& \multicolumn{2}{c}{\text { Dams }} \\
\text { Silver } & \cdot \frac{\mathrm{S} \rho \mathrm{b}}{-\mathrm{rB}} \text { or }\left(\frac{\mathrm{SRb}}{-\mathrm{rB}}\right) \\
\text { Gold } & \cdot \frac{\mathrm{s} \rho \mathrm{b}}{-\mathrm{rB}} \\
\text { Red } & \cdot \frac{\mathrm{sRb}}{-\mathrm{rB}}
\end{array}
$$

Silver . $\quad \frac{S \rho b}{-r B}$ or $\left(\frac{S R b}{-r B}\right)$

Gold . . $\frac{\mathrm{s} \rho \mathrm{b}}{-\mathrm{rB}}$

Silver . $\quad \frac{\mathrm{S} \rho \mathrm{b}}{-\mathrm{rB}}$ or $\left(\frac{\mathrm{SRb}}{-\mathrm{rB}}\right)$

Gold Backcross $\frac{\mathrm{srB}}{-\rho \mathrm{b}}$ or $\frac{\mathrm{sr} B}{-\rho \mathrm{B}}$

Red . $\quad \frac{s R b}{-r B}$

Silver . $\quad \frac{\mathrm{S} \rho \mathrm{b}}{-\mathrm{rB}}$ or $\left(\frac{\mathrm{SRb}}{-\mathrm{rB}}\right)$

Gold $\cdot \quad \cdot \frac{s \rho b}{-r B}$

The indications are that the bracketed genotypes did not occur in the progeny of.JI.

early cleavage divisions which determine the axial organisation of the embryo. It could even have occurred at the first cleavage division, for irregularities of bilaterality of the type noted in the plumage of $\mathrm{J} 2$ are not inconsistent with development from a gastrula in which the two halves differ genetically: the complete cap of silver feathers lies near enough to the midline to be accidentally symmetrical, and the wing bud also has its origin close to the plane of symmetry, so that only a very slight overgrowth of the red side would be required to produce a wholly red wing. As close an association with the two sides of the body would not be expected in the germinal tissue for its precursors, the primordial germ cells, are believed to have their origin external to the gonads and to reach them by amœboid movement through the forming embryonic blood vessels (Willier, I937). 
This is as far back as the phenomenon can be postulated however, in one bird at least, for the data reported present a bar to the idea that it could have had its origin in the zygote itself. If, for example, polyspermy had resulted in double fertilisation, the Light Sussex ovum nucleus might have fused with a sperm to produce the expected heterozygous constitution in the cells of one part of the organism, while the remaining part developed from purely R.I.R. chromosomes. There is nothing in the breeding behaviour of $\mathrm{J}_{2}$ in disagreement with this but the hypothesis infers that both red plumage and yellow leg colour should be carried by the normal (silver) part of the gonad so that the absence of red, white-legged, birds among the progeny of Ji would require explanation. This might be a matter of chance : only 22 silvers were identified at hatching and the non-silver group should be about the same magnitude, with half the birds white-legged. As 5 of the 7 golds recorded had white legs this leaves only another 5 or 6 unaccounted for which could have been red or gold. Thus it is not impossible for the absence of this class to be due to chance in sampling, particularly as leg colour could not be determined until the second examination.

There is a further check on the situation in that half the $F_{1}$ silvers ought also to carry red : only 4 silvers have been adequately tested genetically and none threw reds: this assumes a simple mode of inheritance of red but for present purposes this seems justified by the backcross matings reported in table 6 . There, too, it may be noted there were 24 non-silver offspring with an $F_{1}$ silver parent, in any of which red would have been visible if present but only golds and Brown Leghorns are recorded.

Phenotypically also the evidence from the first cross silvers is against the presence of red : among the progeny of $J i$ there are two types of silver males, self colour with black points and "duckwing," with less clearly differentiated female homologues. The latter pattern carried a red bar on the wing but it was the bright red of the Brown Leghorn plumage and not the dark chestnut typical of the R.I.R. On the other hand there was the group of $\mathrm{J}_{2}$ silver offspring of both sexes, which showed clear evidence of their Rhode Island inheritance : most of their dorsal plumage was dark chestnut and gave the impression of R.I.R. birds with a silver Columbian pattern superimposed (see p. 223). Finally, though less reliably, the mismarked feathers on the silver side of $\mathrm{J} I$ himself appeared to be of a lighter shade than the plumage of the other, while the red feathers on the two sides of $\mathrm{J}_{2}$ seemed more alike.

Thus, though nowhere conclusive, all the evidence seems to point in the same direction, namely, to the absence of red in the silver part of the germinal tissue of $\mathrm{Jr}$ and so to the conclusion that he is not the product of double fertilisation. In $\mathrm{J}_{2}$ on the other hand, the findings with regard to plumage and leg colour support such a theory of his origin, yet the abnormalities exhibited by the 
two cocks are of so similar a character as to call for a similar explanation.

An alternative zygotic irregularity where female gamete and polar body united to form one of the first pair of cells and sperm formed, the other is still more unlikely since by itself it fails to account for silvers with yellow legs or red with white. Both mutation and non-disjunction seem out of the question with the number of independently segregating characters observed to be disarranged. As a possible cause, simple chromosome loss suffers the same disadvantage as double fertilisation in that it requires the loss of two independent genes on the red side of both birds plus the loss of the red from the silver side of $J_{1}$. Also as a sex-linked gene, silver, is involved ; sex or size differences of observable magnitude might have been expected in the two sides of both birds.

The suggestion that there is some incompatability between the gametes of the two breeds, which leads to repulsion between the two chromosome sets introduced into the zygote, is attractive, the more so since this particular cross accounts for more (five) of the previously known cases of lateral asymmetry in the fowl than any other breed or cross (Crew and Munro, 1938). There may be, however, less germane reasons for this: whatever the cause of the phenomenon, it is clear that it can only express itself in the presence of heterozygous alleles, or epi- and hypostatic genes, capable of segregating in an observable form. Commercial crosses with well-marked breed differences should provide suitable ground for its appearance. Most of the 14 cases reviewed by Crew and Munro were of such an origin and only two could be regarded with any certainty as purebred; four showed lateral differences in plumage colour but none of these were Light Sussex $\times$ R.I.R. cross, and I I yielded segregations of shank characters. Abnormalities of the latter class may occur more frequently than plumage ones, or it may be that they are more obvious despite the attention automatically drawn to feathering in sex-linked crosses by its use as a criterion of sex. It must be rare for plumage differences to be so perfectly bilateral as they were in JI, and birds apparently marked erratically would be less likely to attract attention. Thus it is improbable that $\mathrm{J}_{2}$ would have been picked up but for the sender's knowledge of the first mosaic cock; the breeder of $J I$ has also stated that he had noticed other but less well-marked cases of the condition in his flock. Similar predisposing causes may have operated in the detection of most of the other 5 cases from Light Sussex $\times$ R.I.R. matings for after Crew (I928) had published a description of the first one all the others were brought to his notice at later dates. Thus the high number of specimens of lateral asymmetry from this particular cross is not in itself sufficient proof of its higher frequency here. The position then appears to be that none of the more straightforward explanations satisfy the conditions which appear to exist in $J_{I}$ while all, with varying degrees of probability, might be capable of 
accommodating the data from J2. Silver and white legs show no indication of linkage ; mutation, translocation, or non-disjunction, would therefore each involve two distinct steps. In a sense this might also apply to chromosome loss but on the other hand it could be regarded as the single act of dropping anything from two to a haploid set of chromosomes. In this respect it would approach the situation expected with double fertilisation where a second sperm is assumed to undergo development in the cytoplasm of the completed zygote : unless there was a reversion to the diploid condition through some atypical cleavage of the kind that has been reported in frogs (Parmenter, 1940) both would result in the presence of unequal numbers of chromosomes on the two sides of the body. The conclusions of Hutt (1929) and Crew and Munro (1938) suggest that this should be accompanied by lateral size differences, and Fischberg's (1948) work gives actual evidence of such distortions in Triton alpestris, but they have not been observed in the present birds.

Again the condition of haploidy, if it could develop in half the body to the extent of sperm formation, would be difficult to identify except by cytological means. It must be inferred, however, that the spermatogonia producing red plumage are either haploid or homozygous for red since otherwise, a much greater proportion of other colours would have been expected among the progeny of both mosaic cocks. In the case of $\mathrm{JI}$ an irregular " reduction" division could have resulted in leaving red in one cell and silver in the other but raises the problem of why yellow legs occur with both red and silver and white legs only with silver.

\section{SUMMARY}

Two $F_{1}$ cocks, products of mating Light Sussex females to R.I.R. males, each exhibited the plumage and leg colour of both parents; in one the colour distribution was almost perfectly bilateral, in the other less so.

In both cases the abnormalities extended to the germinal as well as the somatic tissue. Breeding tests with the second cock suggested that he had one normal testis while the other was producing no sperm which carried the genes for silver plumage or white legs.

With the cock showing the more perfect bilateral asymmetry the situation was similar but the proportion of silver chicks produced was much smaller, and it seemed likely that the "silver" portion of his testis also was deficient and lacked the genetic basis for R.I.R. type plumage. The breeding behaviour of his progeny was normal.

No theory of the origin of the phenomenon could be formulated which would accommodate the data from both cases. 


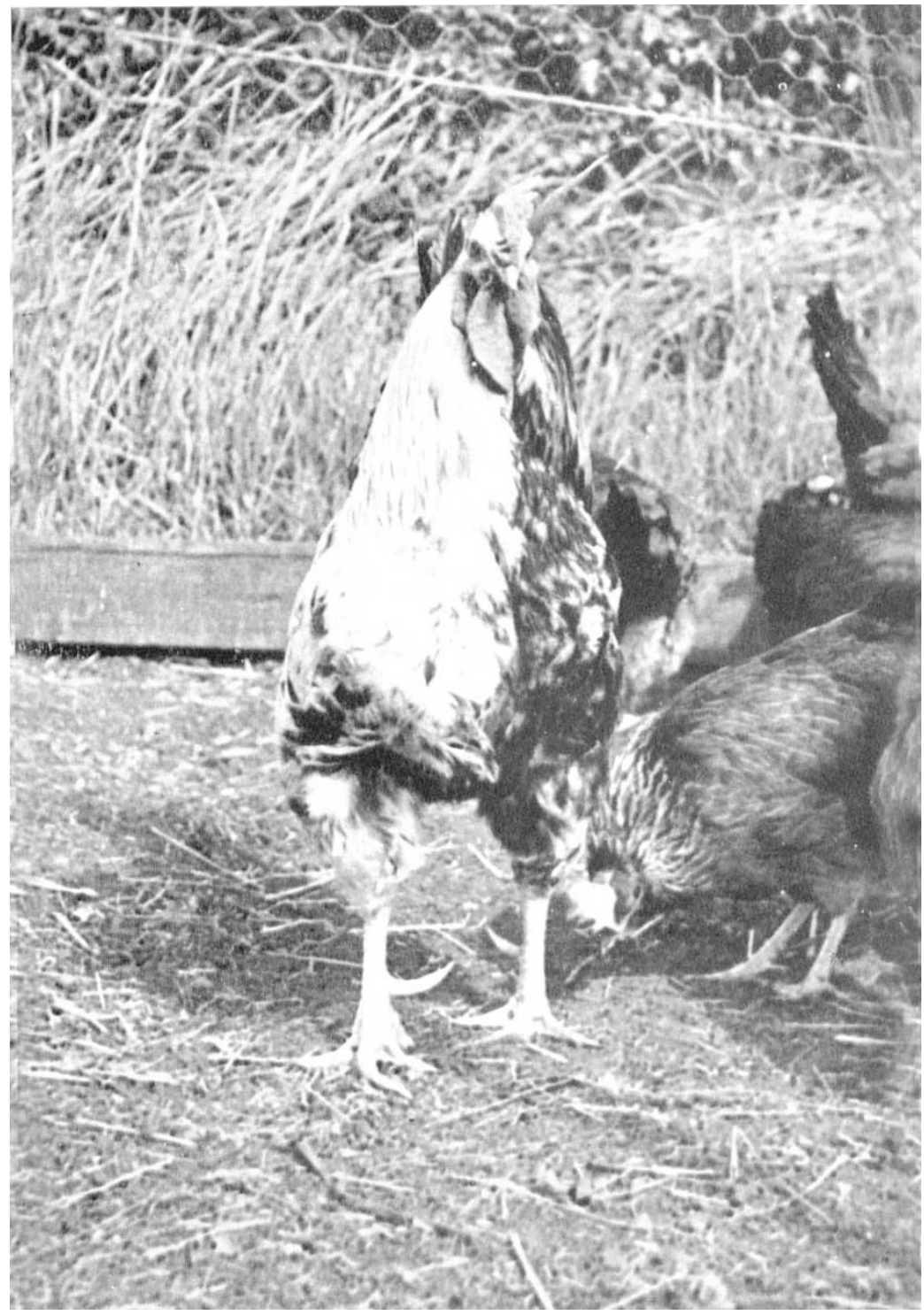

"JI" o 


\section{REFERENCES}

CREW, F. A. E. 1928. A case of lateral asymmetry in the domestic fowl. F. Genet., 20, I 79-I 86 .

CREW, F. A. E., AND MUNRo, s. S. 1938. Gynandromorphism and lateral asymmetry in birds. P.R.S. Edin., $5^{8}$, I I $4^{-1} 34$.

FISCHBERG, M. 1948. Experimentelle Auslösung von Heteroploidie durch Kältbehandlung der Eier von Triton alpestris aus verschiedenen Populationen. Genetica, 24, 213-329.

HUTT, F. B. 1929. Sex dimorphism and variability in the appendicular skeleton of the Leghorn fowl. Poult. Sci., 8, 202-2 I8.

HUTT, F. B. 1949. Genetics of the Fowl. McGraw-Hill Book Co. Inc., New York.

Jull, M. A. 1940. Poultry Breeding, 2nd edition. John Wiley \& Sons Inc., New York.

PARMENTER, c. L. 1940. Chromosome numbers in Rana fusca parthenogenically developed from eggs with known polar body and cleavage histories. F. Morph., 66, $24 \mathrm{I}-26 \mathrm{o}$.

PUNNET, R. C. 1948. Genetic studies in poultry. X. Cream plumage. F. Genet, 48, 327-332.

WILLIER, B. H. 1937. Experimentally produced sterile gonads and the problem of the origin of germ cells in the chick embryo. Anat. Rec., 70, 89-112.

WRIGHT, s., AND EATON, O. N. 1926. Mutational mosaic coat patterns of the guinea-pig. Genetics, 7, 333-351. 